\title{
SUSTENTABILIDADE AMBIENTAL NO CONTEXTO DA INICIAÇÃO CIENTÍFICA NO ENSINO MÉDIO: UMA AÇÃO ESTRATÉGICA FRENTE AO GERENCIAMENTO DE RESÍDUOS DO PROCESSAMENTO QUÍMICO DE RADIOGRAFIAS ODONTOLÓGICAS
}

\author{
Daniel Almeida Ferreira Barbosa ${ }^{1}$ \\ Rebecca Moraes Lima ${ }^{2}$ \\ Luana Sousa Menezes ${ }^{3}$ \\ Davi de Sá Cavalcante ${ }^{4}$ \\ Geibson Góis Brito ${ }^{5}$ \\ Adilia Mirela Pereira Lima Cid ${ }^{6}$ \\ Paulo Goberlânio de Barros Silva ${ }^{7}$ \\ Francisco Samuel Rodrigues Carvalho ${ }^{8}$ \\ Andréa Silvia Walter Aguiar ${ }^{9}$ \\ Lúcio Mitsuo Kurita ${ }^{10}$ \\ Fábio Wildson Gurgel Costa ${ }^{11}$
}

Resumo: os efluentes gerados a partir do processamento radiográfico consistem do líquido revelador, fixador e água de lavagem dos filmes radiográficos, e estes líquidos não devem ser desprezados no meio ambiente sem um tratamento adequado. $O$ objetivo deste trabalho foi realizar uma ação estratégica, na Escola Estadual de Ensino Fundamental e Médio Félix de Azevedo, acerca do Desenvolvimento Sustentável (DS) relacionado aos resíduos oriundos do processamento de radiografias odontológicas. Para tanto, foram realizadas atividades sob 0 protagonismo do aluno do Ensino Médio divididas em três etapas. A primeira etapa consistiu na realização de oficinas temáticas de aprendizagem teórico-práticas, aliadas com a elaboração de material didático, que abordaram temas relativos ao DS. A segunda etapa consistiu na realização de uma análise situacional sobre conhecimentos e atitudes acerca do gerenciamento de resíduos oriundos do processamento químico de radiografias odontológicas com profissionais de um Centro de Especialidades Odontológicas. A terceira etapa consistiu na realização de uma investigação laboratorial sobre alterações das propriedades físico-químicas dos líquidos de processamento radiográfico submetidos a diferentes protocolos experimentais de envelhecimento simulando a prática clínica.

Palavras-chave: Educação Fundamental e Ensino Médio; Oficinas de Trabalho; Meio Ambiente e Saúde Pública; Radiologia.

${ }^{1}$ Universidade Federal do Ceará. E-mail: danielodontologia@gmail.com

${ }^{2}$ Escola Estadual de Ensino Fundamental e Médio Félix de Azevedo. E-mail: rebekamoraes@gmail.com

${ }^{3}$ Escola Estadual de Ensino Fundamental e Médio Félix de Azevedo. E-mail: luanamenezesicee@gmail.com.

${ }^{4}$ Universidade Federal do Ceará. E-mail: davidesacavalcante@hotmail.com

${ }^{5}$ Universidade Federal do Ceará. E-mail: geibsongois@hotmail.com

${ }^{6}$ Universidade Federal do Ceará. E-mail: adiliamirela1@gmail.com .

7 Universidade Federal do Ceará. E-mail: paulo_goberlanio@yahoo.com.br

${ }^{8}$ Universidade Federal do Ceará. E-mail: samuel.rcarvalho@gmail.com

${ }^{9}$ Universidade Federal do Ceará. E-mail: aswaguiar@gmail.com

${ }^{10}$ Universidade Federal do Ceará. E-mail: luciokurita@gmail.com.

${ }^{11}$ Universidade Federal do Ceará. E-mail: fwildson@yahoo.com.br 
Abstract: The effluents generated from radiographic processing consist of the developing liquid, fixative and washing water for the radiographic films, and these liquids must not be discarded in the environment without proper treatment. The aim of this paper was to carry out a strategic action at the State School of Elementary and Secondary Education Félix de Azevedo about sustainable development related to residues from the processing of dental radiographs. Therefore activities were carried out under the leadership of the high school student divided into three stages. Stage 1 consisted of thematic workshops on theoretical and practical learning combined with the preparation of didactic material that addressed themes related to the SD. Stage 2 consisted of conducting a situational analysis on knowledge and attitudes about waste management from the chemical processing of dental radiographs with professionals from a dental specialty center. Stage 3 consisted of conducting a laboratory investigation on changes in the physical-chemical properties of radiographic processing liquids submitted to different experimental aging protocols simulating clinical practice.

Keywords: Primary and Secondary Education; Workshops; Environment and Public Health; Radiology.

\section{Introdução}

A Iniciação Científica (IC) se pauta como uma ação estratégica para fomentar o desenvolvimento científico e tecnológico do país, sendo que até pouco tempo era realizada quase que exclusivamente em Instituições de Ensino Superior. Entretanto, diversas iniciativas vêm ampliando a cobertura dos programas de IC, estimulando que em escolas do Ensino Médio atividades dessa natureza sejam desenvolvidas. Tais atividades têm em comum o objetivo de contribuir para o desenvolvimento de capacidades sociocognitivas dos estudantes, bem como para aprendizagens de natureza científica (BRASíLIA, 2014). Nesse contexto das aprendizagens além dos muros da escola se tem em destaque a necessidade de protagonismo estudantil em relação às temáticas voltadas para a Sustentabilidade Ambiental (SA) e sua relação com a sociedade.

Os debates acerca da temática do Desenvolvimento Sustentável (DS) têm sido uma prática salutar e de grande importância e amplamente difundida nos diferentes setores da sociedade, com vistas à sustentabilidade ambiental aliada à qualidade de vida. Nesse aspecto, a Organização Mundial da Saúde (OMS) reporta que o termo saúde implica não só a ausência de doenças, mas também o bem-estar físico, mental e social do indivíduo (SEGRE; FERRAZ 1997).

Considerando-se a preservação do meio ambiente como um aspecto imprescindível para se conquistar o bem-estar, a temática da saúde ambiental objetiva identificar possíveis agravos ao meio ambiente que possam interferir na saúde humana (BRASIL, 2014). Ainda, o risco para o meio ambiente implica a probabilidade de ocorrerem efeitos adversos, em função da presença de agentes físicos, químicos ou biológicos causadores de condições potencialmente perigosas. 
A radiologia, desde sua invenção há mais de um século, tem sido um importante suporte para o desenvolvimento das Ciências (BAMPI, SECHI, GONÇALVES, 2013), mas apesar de todos os benefícios que os exames imaginológicos têm trazido para a humanidade, muito tem se discutido sobre a deposição dos efluentes gerados pela atividade de revelação dos filmes radiográficos. Reconhece-se que durante todo o procedimento envolvido no processamento químico de filmes radiográficos são produzidos resíduos provenientes de componentes químicos, principalmente o revelador e fixador, apresentando grande periculosidade em relação à segurança ambiental, decorrente do não tratamento dos mesmos ou descarte de forma inadequada (GRIGOLETTO et al., 2011).

Os problemas ambientais que podem ser apontados por esses contaminantes vão desde a contaminação de rios, de lagos e de lençóis freáticos até a sua deposição em áreas nativas, entre outros, e estão relacionados não só ao uso incorreto dos recursos naturais, mas também à falta de tratamento de uma grande parte dos resíduos gerados pela sociedade, inclusive, os resíduos de natureza radiológica (BAMPI; SECHI; GONÇALVES, 2013).

Na prática clínica de Odontologia, a solicitação e uso de exames por imagem são condutas frequentes, entretanto mesmo com o avanço tecnológico e crescentes investimentos nos processos de digitalização das imagens, a grande maioria dos profissionais ainda emprega métodos químicos convencionais no processamento de radiografias, o que gera um risco ao meio ambiente relacionado aos efluentes produzidos do processamento químico radiográfico, bem como em relação aos resíduos sólidos dos componentes do filme radiográfico (GUEDES et al., 2009). O filme ou também conhecido como "película" radiográfica é composto por um filme, lâmina de chumbo, papel preto e envelope plástico (FREITAS, 2004).

Segundo a Resolução 358/05 do Conselho Nacional do Meio Ambiente (CONAMA) e Resolução da Diretoria Colegiada (RDC) no 306/04 da Agência Nacional de Vigilância Sanitária (ANVISA), classificam-se as radiografias insatisfatórias e lâminas de chumbo na categoria de resíduos sólidos do Grupo B (Químicos), os quais devem ser encaminhados ao aterro sanitário industrial para resíduos perigosos do município ou localidade mais próxima ao estabelecimento profissional, ou devem ser submetidos a tratamento de acordo com as orientações do órgão local do meio ambiente, em instalações licenciadas para esse fim (BRASIL, 2004; BRASIL, 2005). Além disso, os efluentes gerados a partir de processamentos radiográficos consistem do líquido revelador, fixador e água de lavagem dos filmes radiográficos, sendo que tais líquidos não devem ser desprezados no meio ambiente sem um tratamento adequado (TESCHKE et al., 2002; GRIGOLETTO et al., 2011), pois consistem em soluções com altas concentrações de prata, de hidroquinona, de quinona, de metol, de tiossulfato de sódio, de sulfito de sódio e de ácido bórico, além de outros químicos altamente tóxicos à saúde ambiental e humana, como 
cianeto, cloreto, ferro, fósforo total, nitrogênio total e sulfito (HOCEVAR; RODRIGUEZ, 2002; FERNANDES et al., 2005).

O cenário anteriormente descrito é palco propício para uma forte discussão sobre a problemática do gerenciamento de tais resíduos, especialmente no ambiente da escola para que o aluno do Ensino Médio possa refletir cada vez mais a respeito de questões relacionadas à SA. A propósito, segundo Ferreira et al. (2003), o aluno sabe que sua inserção em um processo educacional mais aberto do que o desenvolvido pela escola poderá servir na construção do seu próprio futuro enquanto indivíduo.

Assim, reforça-se a importância de ações interdisciplinares que possam levar até a escola conceitos e práticas de IC relacionadas à temática de SA para o Ensino Médio, tais como as mediadas pelo Programa Institucional de Bolsas de Iniciação Científica para o Ensino Médio (PIBIC-EM) firmado entre a Universidade Federal do Ceará (UFC) e o Conselho Nacional de Desenvolvimento Científico e Tecnológico (CNPq).

\section{Metodologia}

\section{Contexto de aplicação e seleção dos alunos bolsistas}

A Escola Estadual de Ensino Fundamental e Médio Félix de Azevedo está situada no Bairro Rodolfo Teófilo em Fortaleza - CE, distante 450 metros do Curso de Odontologia da UFC e a 41 metros do Centro de Especialidades Odontológicas (CEO) Rodolfo Teófilo. Segundo os últimos dados divulgados pelo Instituto Nacional de Estudos e Pesquisas Educacionais Anísio Teixeira (INEP), a escola apresentou indicador de nível socioeconômico médio-baixo, média de 25,3 alunos por turma, percentual médio de docentes com nível superior acima de $93 \%$ e taxa média de reprovação muito baixa (cerca de $1 \%$ ). Em relação a sua infraestrutura, a escola conta com biblioteca, laboratório de informática com computadores e internet banda larga, laboratório de ciências e sala de leitura.

Após aprovação da presente proposta, a diretora da escola foi contatada para que a mesma iniciasse o processo de escolha dos bolsistas. Esta seleção se baseou nos requisitos para participação de alunos constantes no Edital 6/2018 PIBIC-EM 2018-2019. Posteriormente, os alunos elegíveis foram apresentados ao coordenador desta proposta para que fossem discutidas questões relacionadas ao plano de atividades e cronograma relacionados.

\section{Oficinas temáticas teórico-práticas}

Foram realizadas oficinas temáticas de aprendizagem, por meio de metodologia ativa, com o intuito de buscar a mediação entre o saber, sugerindo um trabalho pedagógico interdisciplinar e integrador, objetivando lidar com o 
conhecimento cientificamente acumulado em todas as áreas correlatas para que o bolsista PIBIC-EM pudesse agir em diferentes situações e contextos.

Além do protagonismo do bolsista proveniente da escola de Ensino Médio, as oficinas temáticas teórico-práticas contaram com a participação do proponente do presente projeto, bem como alunos de pós-graduação e PIBIC do Curso de Odontologia da Faculdade de Farmácia, Odontologia e Enfermagem (FFOE) da UFC, com 0 intuito de permitir uma ampla discussão/troca de saberes.

As oficinas temáticas foram realizadas por meio de encontros presenciais tanto na EEFM Félix de Azevedo quanto nas dependências do Curso de Odontologia da FFOE-UFC.

\section{Elaboração de material didático}

Nesta etapa, além de material didático sobre Educação Ambiental a ser divulgado entre todos os alunos da escola, também foi dado destaque para o gerenciamento de resíduos químicos, muito embora todos os resíduos demandem especial atenção. Além disso, a construção do material didático foi pautada na prática dos três $3 R$ 's (reciclagem, redução e reutilização) em virtude da necessidade de se realizar um alerta a respeito do desperdício de produtos, bem como da realização de técnicas radiográficas padronizadas e que evitassem a repetição de exames e, consequentemente, novo processamento químico e descarte de lâmina de chumbo dos filmes radiográficos.

\section{Avaliação de conhecimentos e atitudes sobre Educação Ambiental e gerenciamento de resíduos}

Foi realizado um estudo avaliativo, de natureza quantitativa, transversal e observacional. Os participantes deste estudo foram selecionados por amostragem intencional, sendo os profissionais lotados no CEO Rodolfo Teófilo. O referido local foi escolhido por se tratar de um Centro Odontológico com demanda significativa de procedimentos que requerem a realização de tomadas radiográficas e seu processamento químico, bem como ser um local de fácil acesso ao aluno envolvido, que se localiza a poucos metros de distância da escola de Ensino Médio selecionada para participar deste Edital. Ademais, foram respeitados os preceitos éticos em pesquisa, e o referido projeto foi submetido ao Comitê de Ética em Pesquisa com seres humanos da UFC, através da Plataforma Brasil, tendo sido aprovado com o número 3.066.293. Os voluntários participaram da pesquisa após terem lido, concordado e assinado o Termo de Consentimento Livre e Esclarecido, tendo sido assegurado sigilo quanto a sua identidade e informações prestadas.

Os alunos do Ensino Médio, após terem adquirido conhecimento com a etapa de oficinas temáticas e construção de material didático, participaram de uma pesquisa de campo que teve como objetivo principal avaliar o 
conhecimento e atitudes sobre Educação Ambiental e Gerenciamento de Resíduos produzidos em serviços odontológicos, com foco naqueles oriundos do processamento químico de radiografias. Inicialmente, estes alunos do PIBIC EM foram apresentadas ao questionário e ao roteiro da entrevista.

Foi realizada uma oficina sobre o comportamento do entrevistador, a fim de calibrar os alunos para a aplicação do questionário aos profissionais do CEO. Foi feita uma visita ao CEO com intuito de conhecer a estrutura e apresentar para os alunos a diretoria do serviço.

Foram, então, realizadas visitas ao serviço odontológico para abordagem dos profissionais. Os alunos, acompanhadas dos alunos do PIBIC e dos alunos da pós-graduação em Odontologia, realizaram quinze entrevistas por meio da aplicação de um questionário estruturado em ambiente adequado. Tal instrumento foi construído tendo como base as oficinas temáticas e com protagonismo do aluno bolsista.

Os dados foram tabulados no programa Excel Microsoft. Foi utilizado o software Statistical Package for the Social Sciences (SPSS) versão 20,0 para Windows, no qual as análises foram realizadas adotando uma confiança de 95\%. Foram expressas as frequências absoluta e percentual dos dados categóricos, os quais foram comparados entre as classes profissionais por meio dos testes exatos de Fisher ou qui-quadrado de Pearson.

\section{Investigação laboratorial das alterações físico-químicas de produtos químicos do processamento radiográfico quando submetidos ao envelhecimento}

Durante a terceira etapa do plano de atividades, os alunos foram inseridos em uma pesquisa laboratorial, que teve como objetivo geral avaliar os líquidos utilizados nos processamentos radiográficos e submetidos aos diferentes protocolos experimentais, simulando o seu envelhecimento que ocorre na prática clínica.

O intuito dessa investigação foi avaliar a estabilidade dos produtos utilizados, em longo prazo, durante o processamento químico das radiografias utilizadas. Tal achado seria de grande importância na prática clínica, considerando-se que o uso mais duradouro das soluções evitaria o desperdício, com claros benefícios sob o ponto de vista econômico, e apresentaria notório impacto ambiental, reduzindo a quantidade de produtos químicos desprezados nos efluentes. Além disso, o aluno do Ensino Médio vivenciou, na prática, conhecimentos de química adquiridos na escola, o que se traduziu em uma aprendizagem interdisciplinar entre os espaços "escola" e "universidade".

Para o ensaio de envelhecimento foram analisados o revelador e o fixador radiográficos e a água de lavagem intermediária utilizados no processamento químico das radiografias odontológicas. 
Para a padronização do método, o processamento químico seguiu as recomendações do fabricante dos líquidos radiográficos, em termos de tempo e temperatura exigidos, bem como foi assegurado que após o procedimento, os compartimentos fossem devidamente tampados para se reduzir a degradação natural que ocorre quando da exposição ao ar ambiente. Os grupos experimentais foram definidos de acordo com a quantidade de filmes radiográficos processados, segundo a disposição abaixo:

- Grupo I: revelador, fixador e água de lavagem intermediária novos, não submetidos ao processamento radiográfico.

- Grupo II: revelador, fixador e água de lavagem intermediária submetidos a 10 (dez) processamentos radiográficos.

- Grupo III: revelador, fixador e água de lavagem intermediária submetidos a 20 (vinte) processamentos radiográficos.

- Grupo IV: revelador, fixador e água de lavagem intermediária submetidos a 40 (quarenta) processamentos radiográficos.

Cada grupo foi subdividido quanto ao tempo de envelhecimento dos líquidos. Após sua obtenção, esses foram adequadamente armazenados durante 24 horas, 48 horas, 72 horas e 7 dias até sua análise final.

A distribuição espacial dos componentes presentes nos líquidos de processamento radiográfico foi determinada através das intensidades relativas correspondentes aos picos da microespectrometria Raman (Xplora, Horiba Scientific, Paris, France). A espectrometria Raman se constitui como uma valiosa técnica analítica capaz de mensurar a composição química de amostras de complexos biológicos, como biofluidos, células e tecidos. Além disso, tem sido considerada como uma impressão digital molecular de diferentes substratos, fornecendo informações quantitativas quanto a sua composição química (KANN et al., 2015; KONG et al., 2015).

A distribuição espacial dos componentes foi avaliada através das intensidades relativas de picos obtidos a partir do microespectrofotômetro Raman (Xplora, Horiba Scientific, Paris, França). Um laser de argônio com comprimento de onda de $532 \mathrm{~nm}$ e 3,2 $\mathrm{mW}$ de potência foi usado junto com lente de ampliação de 10Å (Olympus American Inc., Londres, Reino Unido) para obter o foco. As soluções foram adaptadas em recipientes óticos para pa-dronização. Os espectros Raman foram obtidos na faixa entre 600 e $2.000 \mathrm{~cm}-1 \mathrm{com} 3$ (três) acumulações e 10 (dez) segundos de tempo de aquisição. O laser foi empregado em $1 \%$ de potência total, e o foco foi obtido na superfície do líquido.

A aquisição dos espectros Raman foi realizada nas mesmas condições de temperatura e pressão $\left(22^{\circ} \mathrm{C}\right.$ e $\left.1 \mathrm{~atm}\right)$. Dezesseis mililitros de cada solução foram pesquisados. Além disso, foi realizada calibração do aparelho, conforme orientação do fabricante, utilizando sílica como referencial, sendo esta realizada em todos os lasers em todas as grades no aumento de 10x e de 100x.

Todas as análises foram realizadas no mesmo horário durante 24 horas, 48 horas, 72 horas, 120 horas e 144 horas, a fim de detectar possíveis 
alterações ao longo do tempo (Carvalho et al., 2017). Os espectros Raman foram adquiridos no software LabSpec 6 (Horiba). Esses foram processados com correção de linha de base, suavização por método polinomial (SavitzkiGolay) e picos de identificação de posição / intensidade pelos métodos de Gauss e Lorentz para garantir a caracterização e deconvolução de gráficos (KAUPPINEN et al., 1981).

\section{Análise dos dados}

As oficinas temáticas e a etapa de elaboração de material didático foram analisadas de forma subjetiva, sendo observado o rendimento dos alunos durante as atividades. Os dados oriundos da avaliação de conhecimentos e atitudes sobre Educação Ambiental e Gerenciamento de Resíduos por profissionais de um CEO, bem como aqueles advindos da investigação laboratorial foram submetidos a tratamento estatístico.

\section{Resultados e discussão}

\section{Oficinas temáticas}

Foram realizados encontros semanais nas dependências da Clínica de Radiologia da Faculdade de Farmácia, Odontologia e Enfermagem, com a presença das duas bolsistas do projeto, o professor coordenador e dois alunos de Iniciação Científica e alunos da Pós-graduação da disciplina de Radiologia. Durante as oficinas foi estimulado o protagonismo das bolsistas por meio de um trabalho pedagógico interdisciplinar e integrador, buscando realizar uma troca de saberes entre o conhecimento cientificamente acumulado e as vivências em diferentes situações e contextos. Durante os primeiros quatro meses do projeto foram realizadas oficinas temáticas (Figura 1), nas quais foram discutidos os seguintes temas:

(1) "O que é sustentabilidade ambiental e como essa está relacionada no meio em que vivo?".

(2) "Cidadania e sociedade: da sala de aula para a vida".

(2) "Gestão e gerenciamento de resíduos sólidos".

(3) "Gerenciamento dos resíduos radiológicos em serviços odontológicos".

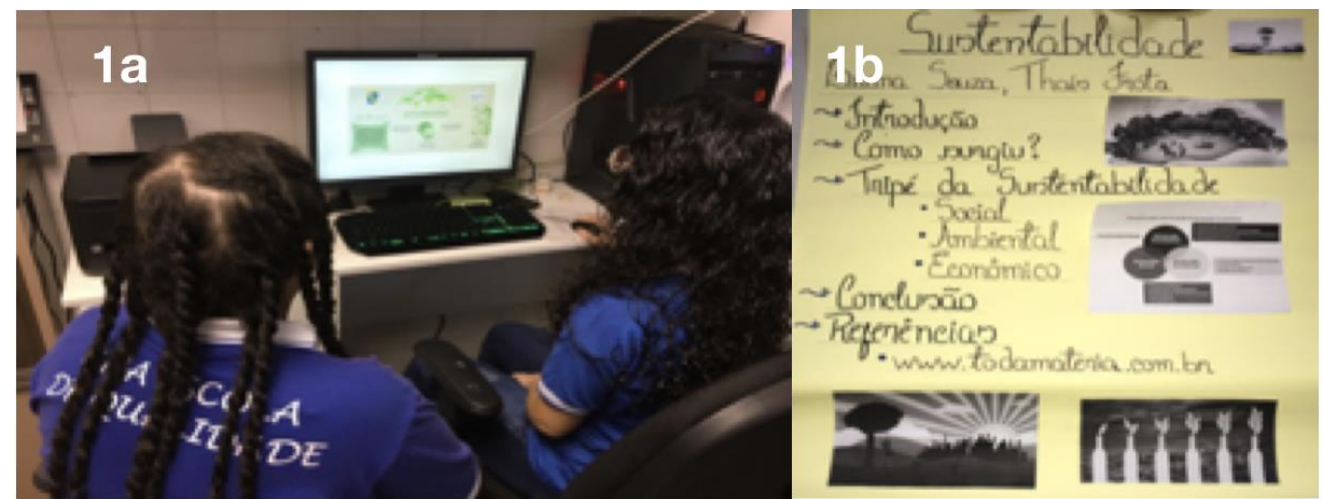

Figura 1: a) Oficina de cartazes; b) Cartaz produzido na oficina. Fonte: Arquivo próprio. 
Em relação às oficinas temáticas, estas geraram produtos a partir dos assuntos abordados, sendo: "O que é SA e como essa está relacionada no meio em que vivo?". Na ocasião, os alunos do PIBIC fizeram explanações acerca dos conceitos de SA e como as práticas humanas interferem no equilíbrio ambiental, por meio de exposição descritiva de slides. Foi realizada uma discussão sobre o tema e foi proposta uma chuva de ideias. E então, diante das ideias levantadas, foi proposta uma oficina de cartazes que foram confeccionados no encontro seguinte.

"Cidadania e sociedade: da sala de aula para a vida" foi outro tema e para abordá-lo foi solicitado que as bolsistas elaborassem uma aula por meio de slides para explanar sobre o assunto. Primeiramente, uma oficina de Power Point (Microsoft) foi realizada para ensinar as ferramentas básicas para a confecção de slides. As alunas montaram as apresentações e no dia da apresentação foram feitas as alterações necessárias para melhorar a aula que, posteriormente, foi apresentada na escola.

"Gestão e gerenciamento de resíduos sólidos" foi outro tema, tendo sido apresentada para as bolsistas uma aula expositiva pelos alunos da Graduação, participantes do PIBIC. Em seguida, houve um momento para retirada de dúvidas, no qual as alunas puderam conhecer melhor sobre o Plano de gestão de resíduos sólidos, qual sua importância e como esse é elaborado.

"Gerenciamento dos resíduos radiológicos em serviços odontológicos" foi tema da realização de uma oficina sobre revelação de filme radiográfico, na qual os alunos do PIBIC ensinaram o passo a passo da revelação às alunas do PIBIC EM. Foi explicado sobre cada passo do processo de revelação e sobre as substâncias utilizadas nesse processamento.

\section{Elaboração de material didático sobre Educação Ambiental}

Em conjunto com o Professor Coordenador, alunos do PIBIC e alunos da pós-graduação, as alunas do PIBIC EM realizaram uma oficina para confecção de um folder buscando criar material didático direcionado às práticas ambientalmente adequadas, em se tratando do gerenciamento de resíduos químicos, as quais irão ser pautadas na Educação Ambiental já que esta oferece aos indivíduos a tomada de consciência da interdependência econômica, social, política e ecológica nos diversos setores da sociedade (DIAS, 1993).

Alves e colaboradores conduziram estudo, cujo objetivo foi elaborar uma cartilha educativa sobre problemas socioambientais, e concluíram que cartilhas educativas podem ser importantes mecanismos de popularização da Ciência, quando atrativas e elaboradas de forma acessível aos diferentes públicos-alvo. Para tanto se faz necessário que o assunto seja abordado de forma criativa e haja um embasamento teórico prévio para a elaboração de tal instrumento (ALVES, GUTJAHR, PONTES, 2019). Tal fato reforça a importância da participação dos alunos do Ensino Médio envolvidos nesta 
pesquisa, que foram protagonistas (Figura 2) de todos os processos do estudo, desde o estudo sobre os temas abordados até a execução da coleta de laboratoriais.

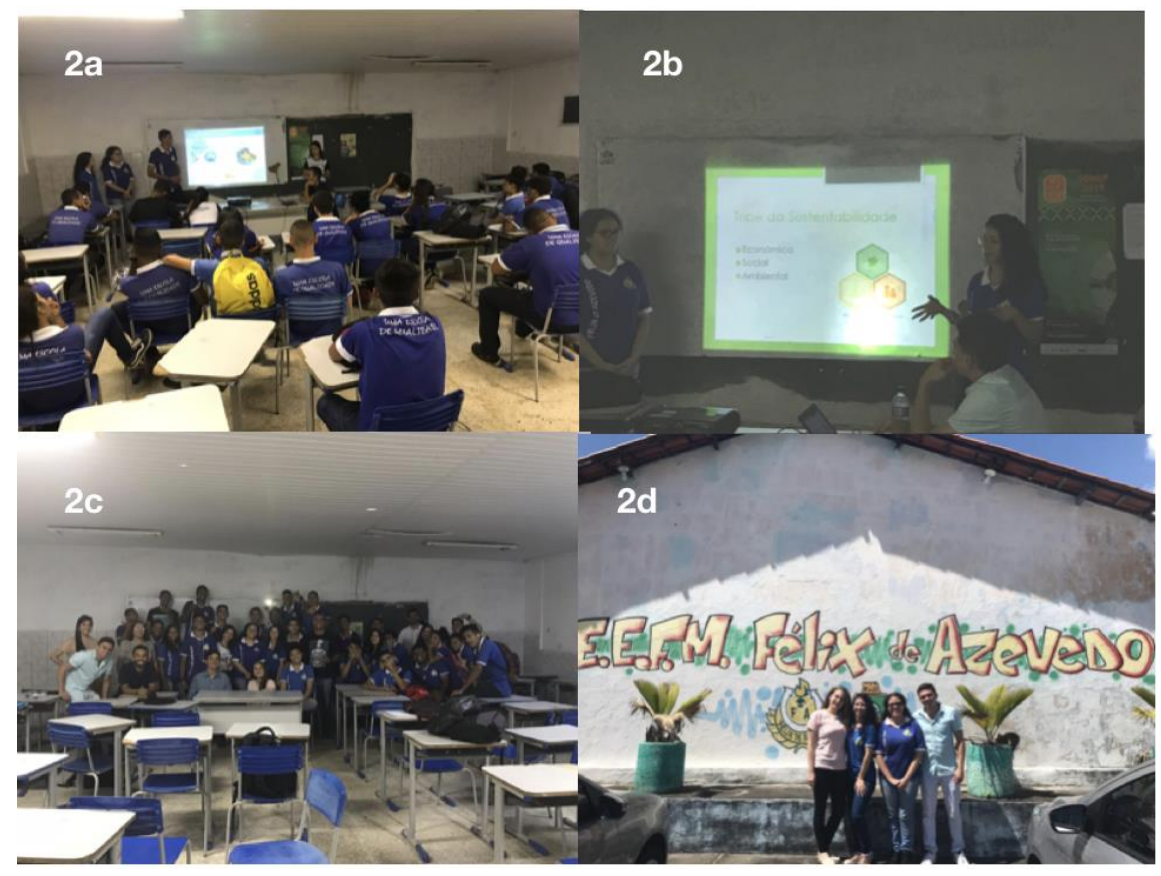

Figura 2: a-c) Apresentação de seminário na Escola. 2d) Alunos de Iniciação Científica da graduação em Odontologia e do Ensino Médio. Fonte: Arquivo próprio.

\section{Avaliação de conhecimentos e atitudes sobre Educação Ambiental e Gerenciamento de Resíduos}

Dos quinze profissionais, oito eram dentistas e sete eram Assistentes de Saúde Bucal (ASB). A maioria da amostra era do sexo feminino $(n=11$; $73 \%)$, havendo maioria significante entre a classe de ASB $(p=0,023)$. A mediana de idade foi 55 anos, e os ASB apresentaram maior prevalência de idade inferior a 55 anos que os dentistas $(p=0,005)$. A instituição formadora de todos os cirurgiões dentistas (CD) foi a UFC ( $n=8 ; 100 \%)$, assim como dos ASB $(n=2 ; 29 \%)$, sem diferença entre as duas categorias $(p=0,127)$. Metade dos profissionais teve formação até 25 anos e maioria significante dos ASB apresenta formação em menos de 25 anos que os dentistas $(p=0,005)$. Dos dentistas avaliados, a maioria $(n=7 ; 88 \%)$ tinha cursado alguma pós-graduação.

Aproximadamente metade dos profissionais conhece 0 que é Desenvolvimento Sustentável (DS) ( $n=8 ; 53 \%)$, a maioria se preocupa com o DS $(n=11 ; 73 \%)$, mas menos da metade aplica o DS em consultório $(n=7$; $47 \%$ ). Não houve diferença entre dentistas e ASB no perfil de conhecimento sobre DS (Tabela 1). 
Tabela 1: Conhecimento sobre Desenvolvimento Sustentável.

\begin{tabular}{|c|c|c|c|c|c|c|c|}
\hline \multirow{3}{*}{ Você sabe o que é DS? } & & & \multicolumn{4}{|c|}{ Profissão } & \multirow[b]{2}{*}{ p-Valor } \\
\hline & \multicolumn{2}{|c|}{ Total } & \multicolumn{2}{|c|}{ Dentista } & \multicolumn{2}{|c|}{ ASB } & \\
\hline & & & & & & & \\
\hline Não & 7 & $47 \%$ & 3 & $38 \%$ & 4 & $57 \%$ & 0,447 \\
\hline Sim & 8 & $53 \%$ & 5 & $63 \%$ & 3 & $43 \%$ & \\
\hline \multicolumn{8}{|c|}{$\begin{array}{l}\text { Você se preocupa com o DS do } \\
\text { planeta? }\end{array}$} \\
\hline Não & 4 & $27 \%$ & 2 & $25 \%$ & 2 & $29 \%$ & 0,876 \\
\hline Sim & 11 & $73 \%$ & 6 & $75 \%$ & 5 & $71 \%$ & \\
\hline \multicolumn{8}{|c|}{$\begin{array}{l}\text { Você aplica algum método de DS } \\
\text { no consultório? }\end{array}$} \\
\hline Não & 8 & $53 \%$ & 5 & $63 \%$ & 3 & $43 \%$ & 0,447 \\
\hline Sim & 7 & $47 \%$ & 3 & $38 \%$ & 4 & $57 \%$ & \\
\hline
\end{tabular}

${ }^{*} p<0,05$, teste exato de Fisher ou qui-quadrado de Pearson (n, \%). DS: Desenvolvimento Sustentável.

Fonte: Arquivo próprio.

Minoria dos profissionais faz tratamento do revelador, sem diferença entre as classes profissionais $(p=0,155)$ e a maioria $(n=9 ; 60 \%)$ envia o mesmo para empresas especializadas. Maioria significante dos dentistas não sabe como descartar o revelador ou o descarta em esgoto comum, enquanto maioria dos ASB sabe que o descarte deve ser direcionado a empresas especializadas $(p=0,033)$. Uma pequena minoria $(n=2 ; 13 \%)$ faz tratamento do fixador, sem diferença entre dentistas e ASB $(p=0,155)$, sendo que os dentistas apresentavam maior frequência de descarte do fixador em esgoto comum ou não sabiam como proceder, diferente dos ASB que o direcionam para empresas especializadas $(p=0,038)$ (Tabela 2 , próxima página).

A maior parte da amostra vê potencial poluidor da água de lavagem, não faz tratamento na água de lavagem e descarta a água de lavagem em esgoto comum. A classe profissional não diferiu significantemente no perfil de descarte da água de lavagem (Tabela 3, próxima página).

Pequena parte da amostra afirma que existe preparação dos resíduos sólidos radiográficos, sem diferença entre dentistas e ASB $(p=0,566)$. A maior parte da amostra faz descartes das radiografias insatisfatórias e das lâminas de chumbo em Lixo comum/lixo hospitalar, sendo os ASB responsáveis por maior prevalência desse método em comparação aos dentistas, que os direcionam significantemente mais para empresas especializadas $(p=0,038$ e $p=0,013$, respectivamente). O principal destino das lâminas chumbo são empresas especializadas no recolhimento, sem diferença entre as categorias profissionais $(p=0,517)$, o principal método de descarte do papel preto é o lixo comum/lixo hospitalar e a maior parte dos profissionais não sabe o destino do papel preto, sem diferença entre dentistas e ASB. O principal método de descarte do involucro plástico citado foi lixo comum/lixo hospitalar, sendo os ASB os maiores responsáveis por essa resposta $(p=0,013)$ e a maior parte dos profissionais não sabe o destino do involucro plástico $(p=0,086)$ (Tabela 4).

Revbea, São Paulo, V. 15, № 3: 92-114, 2020. 
Tabela 2: Gerenciamento dos resíduos.

\begin{tabular}{|c|c|c|c|c|c|c|c|}
\hline & \multirow{2}{*}{\multicolumn{2}{|c|}{ Total }} & \multicolumn{4}{|c|}{ Profissão } & \multirow[b]{2}{*}{ p-Valor } \\
\hline & & & \multicolumn{2}{|c|}{ Dentista } & \multicolumn{2}{|c|}{ ASB } & \\
\hline \multicolumn{8}{|l|}{$\begin{array}{l}\text { No(s) consultório(s) que você } \\
\text { trabalha existe algum tratamento } \\
\text { da solução reveladora antes de seu } \\
\text { descarte? }\end{array}$} \\
\hline Não & 13 & $87 \%$ & 6 & $75 \%$ & 7 & $100 \%$ & 0,155 \\
\hline Sim & 2 & $13 \%$ & 2 & $25 \%$ & 0 & $0 \%$ & \\
\hline \multicolumn{8}{|l|}{$\begin{array}{l}\text { Como é feito o descarte da solução } \\
\text { reveladora? }\end{array}$} \\
\hline Esgoto comum & 2 & $13 \%$ & $2^{*}$ & $25 \%$ & 0 & $0 \%$ & 0,033 \\
\hline Enviado para empresa especializada & 9 & $60 \%$ & 2 & $25 \%$ & $7^{*}$ & $100 \%$ & \\
\hline $\begin{array}{l}\text { Neutralizado antes de descartá-la } \\
\text { com grande quantidade de água no } \\
\text { esgoto }\end{array}$ & 1 & $7 \%$ & 1 & $13 \%$ & 0 & $0 \%$ & \\
\hline Não sabe & 3 & $20 \%$ & $3^{*}$ & $38 \%$ & 0 & $0 \%$ & \\
\hline \multicolumn{8}{|l|}{$\begin{array}{l}\text { No(s) consultório(s) que você } \\
\text { trabalha existe algum tratamento } \\
\text { da solução fixadora antes de seu } \\
\text { descarte? }\end{array}$} \\
\hline Não & 13 & $87 \%$ & 6 & $75 \%$ & 7 & $100 \%$ & 0,155 \\
\hline Sim & 2 & $13 \%$ & 2 & $25 \%$ & 0 & $0 \%$ & \\
\hline \multicolumn{8}{|l|}{$\begin{array}{l}\text { Como é feito o descarte da solução } \\
\text { fixadora? }\end{array}$} \\
\hline Esgoto comum & 2 & $13 \%$ & $2^{*}$ & $25 \%$ & 0 & $0 \%$ & 0,038 \\
\hline Enviado para empresa especializada & 10 & $67 \%$ & 3 & $38 \%$ & $7^{*}$ & $100 \%$ & \\
\hline Não sabe & 3 & $20 \%$ & $3^{*}$ & $38 \%$ & 0 & $0 \%$ & \\
\hline
\end{tabular}

Tabela 3: Gerenciamento dos resíduos.

\begin{tabular}{|c|c|c|c|c|c|c|c|}
\hline & & & Pro & ssão & & & \\
\hline & Tota & & DeI & sta & AS & & p-Valor \\
\hline $\begin{array}{l}\text { Você vê potencial poluidor na água de } \\
\text { lavagem? }\end{array}$ & & & & & & & \\
\hline Não & 6 & $40 \%$ & 2 & $25 \%$ & 4 & $57 \%$ & 0,348 \\
\hline Sim & 8 & $53 \%$ & 5 & $63 \%$ & 3 & $43 \%$ & \\
\hline Não sabe & 1 & $7 \%$ & 1 & $13 \%$ & 0 & $0 \%$ & \\
\hline $\begin{array}{l}\text { No(s) consultório(s) que você trabalha } \\
\text { existe algum tratamento para água de } \\
\text { lavagem? }\end{array}$ & & & & & & & \\
\hline Não & 13 & $87 \%$ & 7 & $88 \%$ & 6 & $86 \%$ & 0,919 \\
\hline Sim & 2 & $13 \%$ & 1 & $13 \%$ & 1 & $14 \%$ & \\
\hline Como a água de lavagem é descartada & & & & & & & \\
\hline Esgoto comum & 10 & $67 \%$ & 3 & $38 \%$ & 7 & $100 \%$ & 0,087 \\
\hline Enviado para empresa especializada & 1 & $7 \%$ & 1 & $13 \%$ & 0 & $0 \%$ & \\
\hline $\begin{array}{l}\text { Diluído em água antes de descartá-la } \\
\text { em esgoto comum }\end{array}$ & 1 & $7 \%$ & 1 & $13 \%$ & 0 & $0 \%$ & \\
\hline Não sabe & 3 & $20 \%$ & 3 & $38 \%$ & 0 & $0 \%$ & \\
\hline
\end{tabular}


Tabela 4: Gerenciamento dos resíduos.

\begin{tabular}{|c|c|c|c|c|c|c|c|}
\hline & & & Pro & ssão & & & \\
\hline & Tota & & De & ista & ASB & & p-Valor \\
\hline Não & 6 & $40 \%$ & 3 & $38 \%$ & 3 & $43 \%$ & 0,566 \\
\hline Sim & 5 & $33 \%$ & 2 & $25 \%$ & 3 & $43 \%$ & \\
\hline Não sabe & 4 & $27 \%$ & 3 & $38 \%$ & 1 & $14 \%$ & \\
\hline $\begin{array}{l}\text { Como é feito o descarte das radiografias } \\
\text { insatisfatórias }\end{array}$ & & & & & & & \\
\hline Lixo comum/lixo hospitalar & 10 & $67 \%$ & 3 & $38 \%$ & $7^{*}$ & $100 \%$ & 0,038 \\
\hline Enviado para empresa especializada & 3 & $20 \%$ & $3^{*}$ & $38 \%$ & 0 & $0 \%$ & \\
\hline Não sabe & 2 & $13 \%$ & $2^{*}$ & $25 \%$ & 0 & $0 \%$ & \\
\hline $\begin{array}{l}\text { Como é feito o descarte das lâminas de } \\
\text { chumbo? }\end{array}$ & & & & & & & \\
\hline Lixo comum/lixo hospitalar & 9 & $60 \%$ & 2 & $25 \%$ & $7^{*}$ & $100 \%$ & 0,013 \\
\hline Enviado para empresa especializada & 2 & $13 \%$ & $2^{*}$ & $25 \%$ & 0 & $0 \%$ & \\
\hline Não sabe & 4 & $27 \%$ & $4^{*}$ & $50 \%$ & 0 & $0 \%$ & \\
\hline $\begin{array}{l}\text { Após este ato, qual o destino destas } \\
\text { películas de chumbo? }\end{array}$ & & & & & & & \\
\hline Catador/reciclador & 1 & $7 \%$ & 1 & $13 \%$ & 0 & $0 \%$ & 0,517 \\
\hline Empresa especializada no recolhimento & 6 & $40 \%$ & 2 & $25 \%$ & 4 & $57 \%$ & \\
\hline Lixo comum & 2 & $13 \%$ & 1 & $13 \%$ & 1 & $14 \%$ & \\
\hline Não sabe & 6 & $40 \%$ & 4 & $50 \%$ & 2 & $29 \%$ & \\
\hline Como é feito o descarte do papel preto? & & & & & & & \\
\hline Lixo comum/lixo hospitalar & 10 & $67 \%$ & 4 & $50 \%$ & 6 & $86 \%$ & 0,187 \\
\hline Enviado para empresa especializada & 2 & $13 \%$ & 1 & $13 \%$ & 1 & $14 \%$ & \\
\hline Não sabe & 3 & $20 \%$ & 3 & $38 \%$ & 0 & $0 \%$ & \\
\hline $\begin{array}{l}\text { Após este ato, qual o destino deste pape } \\
\text { preto? }\end{array}$ & & & & & & & \\
\hline Catador/reciclador & 1 & $7 \%$ & 1 & $13 \%$ & 0 & $0 \%$ & 0,485 \\
\hline Empresa especializada no recolhimento & 4 & $27 \%$ & 1 & $13 \%$ & 3 & $43 \%$ & \\
\hline Lixo comum & 2 & $13 \%$ & 1 & $13 \%$ & 1 & $14 \%$ & \\
\hline Não sabe & 8 & $53 \%$ & 5 & $63 \%$ & 3 & $43 \%$ & \\
\hline $\begin{array}{l}\text { Como é feito o descarte do invólucro de } \\
\text { plástico? }\end{array}$ & & & & & & & \\
\hline Lixo comum/lixo hospitalar & 9 & $60 \%$ & 2 & $25 \%$ & $7^{*}$ & $100 \%$ & 0,013 \\
\hline Outro fim & 3 & $20 \%$ & $3^{*}$ & $38 \%$ & 0 & $0 \%$ & \\
\hline Não sabe & 3 & $20 \%$ & $3^{*}$ & $38 \%$ & 0 & $0 \%$ & \\
\hline Após este ato, qual o destino deste plás & & & & & & & \\
\hline Catador/reciclador & 1 & $7 \%$ & 1 & $13 \%$ & 0 & $0 \%$ & 0,086 \\
\hline Empresa especializada no recolhimento & 4 & $27 \%$ & 0 & $0 \%$ & 4 & $57 \%$ & \\
\hline Lixo comum & 3 & $20 \%$ & 2 & $25 \%$ & 1 & $14 \%$ & \\
\hline Não sabe & 7 & $47 \%$ & 5 & $63 \%$ & 2 & $29 \%$ & \\
\hline $\begin{array}{l}\text { Na época de faculdade/Curso o assunto } \\
\text { carte de resíduos radiológicos foi abord }\end{array}$ & & & & & & & \\
\hline Não & 9 & $60 \%$ & 5 & $63 \%$ & 4 & $57 \%$ & 0,217 \\
\hline Sim & 4 & $27 \%$ & 1 & $13 \%$ & 3 & $43 \%$ & \\
\hline Não sabe & 2 & $13 \%$ & 2 & $25 \%$ & 0 & $0 \%$ & \\
\hline
\end{tabular}


A maior parte das faculdades não aborda o assunto, independente se centros de formação técnica ou de Ensino Superior. Considerando a idade média de todos os profissionais que foi de 53,8 11,05 anos, tal fato se explica pela ausência de processos seletivos para o preenchimento de vagas em Unidades de Atenção Secundária no Estado do Ceará, o que acarreta um envelhecimento do corpo de profissionais.

A formação profissional dos cirurgiões dentistas (CD) entrevistados aconteceu na UFC, provavelmente, em virtude de ser o único Curso de Odontologia do Estado do Ceará até o ano de 1998. Em relação aos profissionais ASB, a instituição formadora mais prevalente foi a UFC, entretanto não houve diferença estatisticamente significante para outras entidades promotoras de cursos voltados para a formação de ASB. Esta distribuição homogênea pode ser explicada pelo fato de haver várias instituições que possuem cursos de formação profissional de auxiliares.

A sociedade contemporânea considera o Desenvolvimento Sustentável (DS) como a melhor maneira de abordar esses problemas complexos e interrelacionados em prol das gerações atuais e futuras e da integridade do planeta (WAAS et al., 2010). Entretanto, pouco mais da metade dos profissionais entrevistados afirma conhecer o DS. Ainda assim, têm preocupação com DS, e talvez isso seja reflexo do fato de o conceito ter surgido na década de 1980 como um princípio orientador desejável para a comunidade mundial, em que o DS seria uma busca e manutenção pela "qualidade de vida" (BERT et al., 2009). Kaster e colaboradores conduziram um estudo com quarenta participantes, no qual se encontrou que $90 \%$ dos profissionais afirmaram ter o conhecimento sobre DS, isto evidencia uma diferença em relação ao presente estudo que encontrou 53\% em uma amostra de quinze indivíduos (KASTER et al., 2012).

Em relação à aplicabilidade do DS nos consultórios, sete dos quinze entrevistados afirmaram praticá-lo. Em uma pesquisa envolvendo cento e quarenta estudantes no quinto ano do curso de Odontologia da Universidade de Manchester em 2010, 36\% dos indivíduos responderam ter ciência de que uma prática odontológica gerava resíduos não recicláveis, mas achavam que a quantidade era menor, ao passo que $24 \%$ não haviam considerado a questão acerca da produção de lixo não reciclável (KINAKH, 2015).

Segundo dados da Associação de Eco Odontologia, entre 66 e $75 \%$ dos 120.000 consultórios odontológicos dos EUA ainda usam raios-x tradicionais e exigem o descarte de 4,8 mil folhas de chumbo e 28 mil litros de fixador de raios- $x$ todos os anos" (POCKRASS, 2010). Os efluentes geradores, a partir do processamento radiográfico incluem substâncias, reveladora e fixadora, além da água utilizada na lavagem intermediária. Tais efluentes são considerados substâncias químicas altamente tóxicas pelos órgãos reguladores e, portanto, não podem ser descartados no meio ambiente sem tratamento adequado (MANZI et al., 2015). Os profissionais entrevistados relataram que o revelador deve ser enviado para uma empresa especializada para que seja realizado o 
descarte, entretanto, a maioria afirma não ser necessário realizar nenhum tipo de tratamento nesta substância antes do descarte. Em virtude do liquido revelador possuir um $\mathrm{PH}$ básico, cerca de 7 a 9 , deve-se realizar a neutralização da substância, para tanto se pode utilizar a soda cáustica na forma de solução ou ácido muriático. Quimicamente, a reação oriunda entre uma substância básica e outra ácida resulta em água e sal e, consequentemente, ocorre 0 processo de neutralização. Mendes e colaboradores ainda relatam a utilização de ácido acético para o processo de neutralização do revelador, nesta técnica se faz o uso de uma fita indicadora ( $\mathrm{pH}$ entre 7 e 9) e 10 litros de água e $100 \mathrm{~mL}$ de vinagre comum, que são adicionados para cada 1 litro de revelador (MENDES et al., 2005).

Em relação ao descarte e tratamento do fixador, $87 \%$ dos profissionais não realiza nenhum tratamento dessa solução após a utilização e os CD relataram descartar em esgoto comum ou não saber o que fazer, ao passo que os ASB direcionam para empresas especializadas. Este dado confronta com os achados de Kaster e colaboradores de que $35 \%$ dos profissionais relataram lançar este efluente diretamente no esgoto comum, 35\% enviam para empresa especializada, $22,5 \%$ diluem em água antes de descartar no esgoto comum e $7,5 \%$ neutralizam antes de descartar em esgoto comum. No estudo de Kinakh, $13 \%$ dos estudantes responderam ser o fixador o material odontológico com maior potencial de danos ao meio ambiente, sendo o amálgama o material com maior potencial (KINAKH, 2015).

A água utilizada na lavagem intermediária também gera efluentes, contendo todos os componentes do revelador e do fixador e de seus produtos de reação: hidroquinona, quinona, metol, tiossulfato de sódio, sulfito de sódio, enxofre elementar, ácido acético, acetado de sódio, ácido bórico e outros, além de prata, sob a forma de íons complexos com S2O3 (CARVALHO, 2000). No presente estudo, os profissionais consideram a água da lavagem intermediária com potencial poluidor, entretanto não realizam tratamento e a descartam no esgoto comum. É necessário realizar a recuperação dos sais de prata da água de lavagem intermediária associado com a neutralização antes do descarte em esgoto, em função da presença de resíduos oriundos especialmente da solução reveladora (FERNANDES et al., 2005; GRIGOLETTO, 2010).

Neste estudo, tanto CD como ASB afirmaram existir uma preparação dos resíduos sólidos do processamento radiográfico, sendo que grande parte dos profissionais faz o descarte em lixo comum ou lixo hospitalar, achados estes semelhantes aos do estudo de Kaster em 2012, no qual $15,0 \%$ dos participantes disseram desprezar a película radiográfica insatisfatória em lixo comum; 42,5\% em lixo hospitalar; e 40,0\% afirmaram enviar para uma empresa especializada. Este dado é alarmante, visto que ainda nos dias de hoje, este estudo encontrou que $67 \%$ dos profissionais descartam as radiografias insatisfatórias no lixo comum/lixo hospitalar, e que em muitas situações este lixo é depositado em aterros sanitários (GUEDES et al., 2009). 
O papel preto não possui em sua composição chumbo, entretanto, quando exposto à radiação $X$ também foi detectado o chumbo. Possivelmente, quando os raios $X$ atravessam o filme, deve ocorrer a contaminação do papel preto pelo deslocamento do chumbo contido na lâmina de chumbo (GUEDES et al., 2009B). De acordo com esta informação, o papel preto deve ser descartado por uma empresa especializada como respondido por $27 \%$ dos participantes deste estudo, enquanto $47 \%$ dos profissionais não sabia qual o destino de descarte do papel preto.

Apesar de ser clara a legislação acerca das consequências da infração, os efluentes e os resíduos gerados pelos serviços de diagnóstico por imagem seguem em geral os seguintes caminhos: algumas instituições lançam tanto os efluentes (Soluções de fixador, de revelador e de água de lavagem) quanto os resíduos (filmes radiográficos) no meio ambiente, sem nenhum tratamento adequado (FERNANDES et al., 2005).

A maior parte das Faculdades não aborda o assunto, independente se centros de formação técnica ou de Ensino Superior. Os aspectos ambientais da sustentabilidade são familiares aos estudantes de Odontologia da Universidade de Manchester, no entanto, os dados mostram que ainda há muito a fazer em um esforço para promover compreensão e consciência da sustentabilidade dentro do currículo odontológico (BERT et al., 2009).

Por conseguinte, deve-se estimular que acadêmicos e profissionais da Odontologia participem de discussões para aprender mais sobre sustentabilidade, para que se comprometam a usar "inovações que tornar a prática ainda mais rentável e ambientalmente mais segura" (KINAKH, 2015).

\section{Investigação laboratorial das alterações físico-químicas de produtos químicos do processamento radiográfico quando submetidos ao envelhecimento}

Previamente aos testes laboratoriais, os alunos bolsistas participaram de um momento teórico no qual foram explicados, de maneira geral, a natureza e produção dos raios-x. Além disso, também foram dadas explicações sobre o processamento químico, produtos utilizados, sempre procurando correlacionar o aprendizado de física e química básica aprendido na Escola com os conhecimentos peculiares à radiologia Odontológica.

Os alunos acompanharam os procedimentos relativos à execução da pesquisa, incluindo a leitura das amostras pela espectrometria Raman. Neste momento, muitos conceitos relativos aos princípios físicos puderam ser discutidos, reforçando ainda mais a correlação Universidade-Escola.

Os resultados desta etapa do projeto foram importantes para o conhecimento do efeito do envelhecimento das soluções processadoras utilizadas no âmbito da clínica odontológica. Por meio da microespectroscopia Raman foram coletados os dados relativos à distribuição espacial dos componentes presentes: revelador, água intermediária e fixador.

revista brasileira educação ambiental 
Os espectros das soluções analisadas estão descritos na Figura 3.

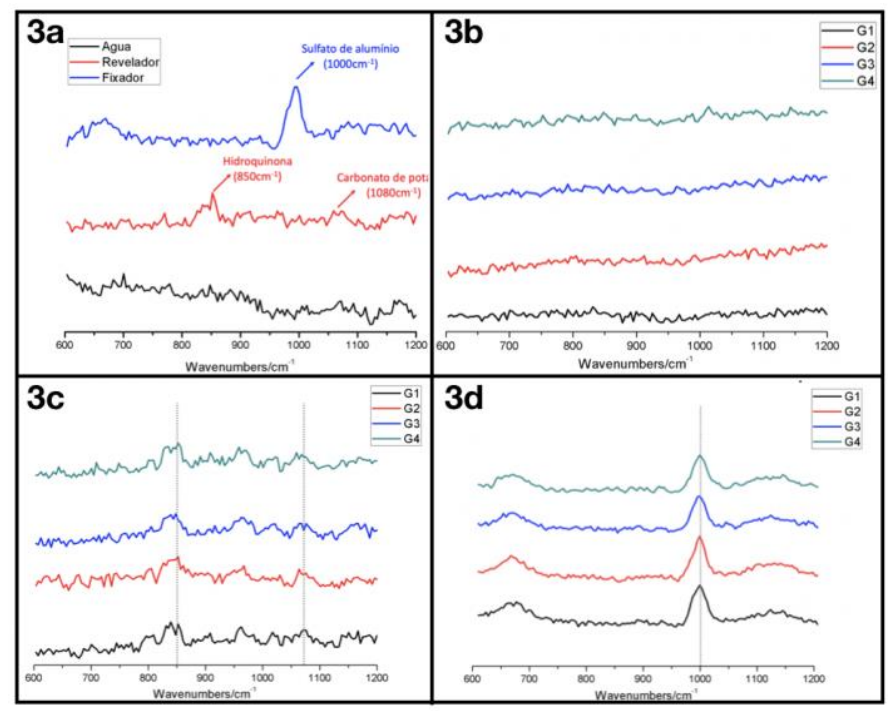

Figuras 2. a) Espectros Raman da água (preto), revelador (vermelho) e fixador (azul). b) Espectros Raman água nos grupos G1, G2, G3 e G4. c) Espectros Raman revelador nos grupos G1, G2, G3 e G4. Picos $850 \mathrm{~cm}-1$ e $1080 \mathrm{~cm}-1$ exibindo o mesmo padrão. d) Espectros Raman fixador nos grupos G1, G2, G3 e G4. Pico $1000 \mathrm{~cm}-1$ exibindo o mesmo padrão.

Fonte: Arquivo próprio.

A solução reveladora é composta por hidroquinona (paradihidroxibenzeno), carbonato de potássio e dietilenoglicol. Observa-se através da superposição dos gráficos como picos específicos do revelador: hidroquinona $(850 \mathrm{~cm}-1)$ e carbonato de potássio $(1080 \mathrm{~cm}-1)$.

A solução fixadora é composta por bissulfeto de sódio, sulfato de alumínio e amônia. Observa-se através da superposição dos gráficos como picos específicos do fixador: sulfato de alumínio $(1000 \mathrm{~cm}-1)($ SMITH, DENT 2005).

Os picos observados nos três líquidos se repetem na região entre 1400 cm-1 a 2000cm-1 caracterizando um mesmo composto (SMITH, DENT, 2005) o que sugere uma possível interferência do recipiente utilizado para realização das leituras. Por esse motivo foram removidos do gráfico.

\section{a. Fator processamento}

As soluções água, revelador e fixador foram divididas em grupos de acordo com a quantidade de processamentos radiográficos realizados, sendo G1 (nenhum), G2 (dez), G3 (vinte) e G4 (quarenta). Não foram observadas alterações significativas referentes aos grupos após diferentes quantidades de processamentos radiográficos realizados conforme observado nas figuras $3 \mathrm{~b}$ $3 d$.

b. Fator tempo de envelhecimento das soluções 
As soluções água, revelador e fixador tiveram seus espectros Raman obtidos em diferentes tempos, sendo estes: 24, 48, 72, 120 e 144 horas após a realização das tomadas radiográficas. Não foram observadas alterações significativas referentes aos grupos após diferentes intervalos de tempo, conforme observado nas Figuras 4, 5 e 6.

A

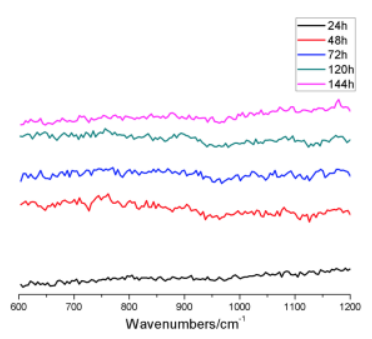

c

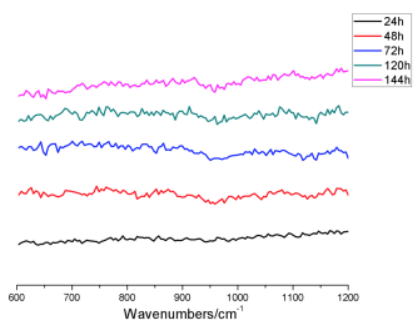

B
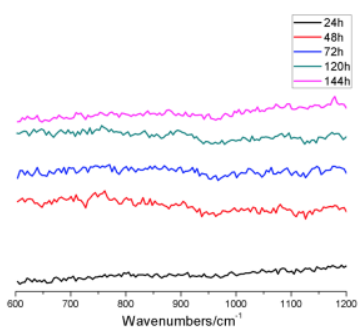

D

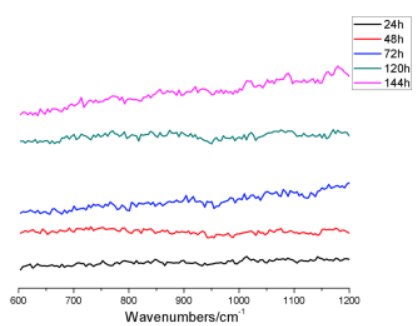

Figuras 4. Espectros Raman da água nos tempos 24, 48, 72, 120 e 144 horas. A. Grupo G1. B. Grupo G2. C. Grupo G3. D. Grupo G4. Fonte: Arquivo próprio.

A

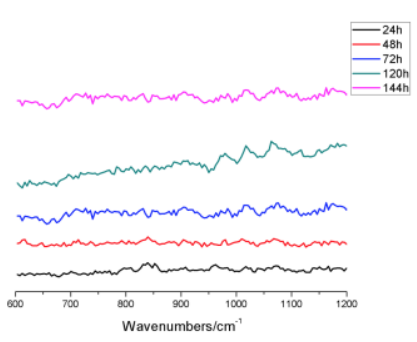

c

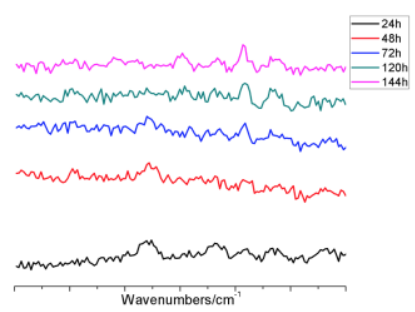

B

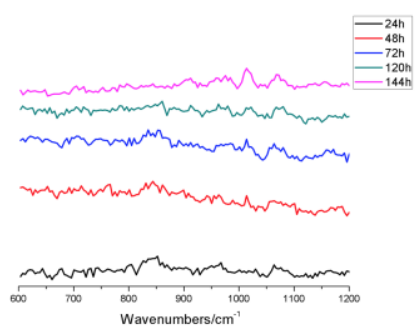

D

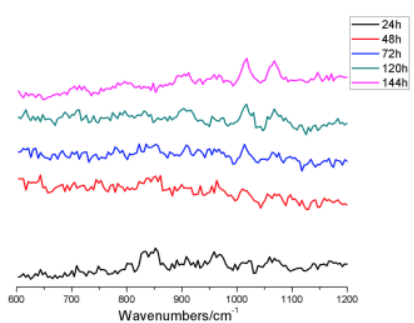

Figuras 5. Espectros Raman do revelador nos tempos 24, 48, 72, 120 e 144 horas. A. Grupo G1. B. Grupo G2. C. Grupo G3. D. Grupo G4. Fonte: Arquivo próprio. 

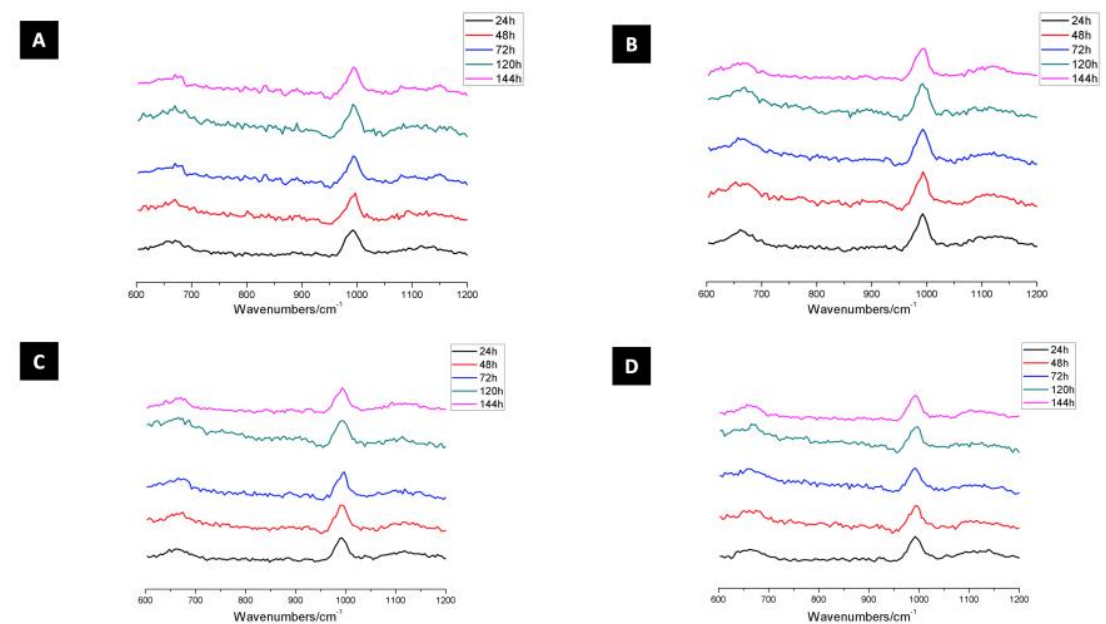

Figuras 6. Espectros Raman do fixador nos tempos 24, 48, 72, 120 e 144 horas. A. Grupo G1. B. Grupo G2. C. Grupo G3. D. Grupo G4. Fonte: Arquivo próprio.

A espectrometria Raman se constitui como uma valiosa técnica analítica capaz de mensurar a composição química de amostras de complexos biológicos, como biofluidos, células e tecidos. Além disso, tem sido considerada como uma impressão digital molecular de diferentes substratos, fornecendo informações quantitativas quanto a sua composição química (KANN et al., 2015; KONG et al., 2015). Entretanto, a presença de picos em regiões semelhantes pode dificultar a identificação de picos específicos de determinados componentes de uma solução (CARVALHO et al., 2017). Esses achados dificultam a identificação de picos específicos de cada solução analisada, somado ao fato de não existirem estudos prévios que caracterizaram as soluções de processamento radiográfico.

$\mathrm{O}$ advento da tecnologia proporcionou o desenvolvimento da radiografia digital, que dispensa a utilização de soluções reveladoras e fixadoras, apesar do custo relativamente baixo, diversos países mantém a prática de processamento radiográfico químico convencional (GRIGOLETTO et al., 2011). Dessa forma, o presente estudo ressalta que devem ser avaliados os líquidos para utilizá-los o máximo possível.

A espectroscopia Raman foi utilizada na presente avaliação dos compostos químicos das amostras, uma vez que pode fornecer informações importantes em relação à composição química com substâncias de modo não destrutivo (CARVALHO et al., 2017), permitindo a reutilização do material utilizado no experimento, além de não requerer preparação da amostra.

Existe uma dificuldade que pode ser encontrada durante a avaliação de íons como a prata, uma vez que seus picos podem estar associados aos picos de outras substâncias. Uma alternativa é a utilização do espalhamento Raman com superfície aumentada (SERS), que tem sido intensamente pesquisado por muitos anos como uma grande técnica potencial para detecção de ultra-traço. É geralmente reconhecido que dois mecanismos diferentes estão envolvidos na SERS - um é o reforço causado pela transferência de carga entre a molécula e 
superfície metálica adjacente, e o outro é o aprimoramento eletromagnético local, que se origina da excitação de oscilações coletivas de elétrons livres em metais nobres ou de transição, tais como: Ag, Au, Pt e Ru (LIANG et al., 2009). Uma alternativa seria a avaliação da qualidade da imagem radiográfica gerada.

\section{Conclusões}

Em suma, foi possível perceber a importância da Iniciação Científica na formação escolar das bolsistas no tocante à temática de SA com enfoque odontológico, bem como o potencial dos alunos e, também, suas deficiências, que foram trabalhadas ao longo deste período. As oficinas temáticas tiveram um papel de destaque, visto que apresentaram os produtos confeccionados entre os colegas, desenvolvendo assim habilidades com o público, oratória e síntese de ideias.

A presente investigação observou que mais da metade dos profissionais se importa com o DS, entretanto os CD não sabem como descartar o revelador ou o fazem de maneira errônea, descartando diretamente no esgoto comum, enquanto os ASB direcionam para empresa especializada. A maioria dos profissionais não faz tratamento para as soluções fixadoras, bem como para a água de lavagem intermediária, apesar de enxergarem potencial poluidor.

A inserção da Universidade na Escola também foi possível de ser fortalecida com o desenvolvimento de uma etapa de pesquisa, na qual os alunos puderam adentrar ao meio científico, tendo experiências com outros profissionais de saúde por meio de pesquisa baseada em questionário estruturado, bem como vivenciar na prática conceitos adquiridos na Escola que puderam ser confrontados com a investigação laboratorial realizada.

\section{Agradecimentos}

Programa Institucional de Bolsas de Iniciação Científica Para o Ensino Médio (PIBIC-EM), Universidade Federal do Ceará

\section{Referências}

ALVES, R.J.M.; GUTJAH, A.L.N.; PONTES, A.N. Processo metodológico de elaboração de uma cartilha educativa socioambiental e suas possíveis aplicações na sociedade. Revista Brasileira de Educação Ambiental, São Paulo, v. 14, n. 2, p. 69-85, 2019.

BRASIL. Conselho Nacional do Meio Ambiente. Resolução Conama $n^{\circ} 358$, de 29 de abril de 2005. Dispõe sobre o tratamento e a disposição final dos resíduos dos serviços de saúde e dá outras providências. Brasília, DF: Diário Oficial da União oㅜ 84, de 4 de maio de 2005; Seção I, p. 63-65. 
BRASIL. Ministério da Educação. Manual Operacional de educação integral, 2014. Dispõe sobre os conceitos relacionados à educação básica e a educação integral. Disponível em:<http://portal.mec.gov.br/index.php?option= com docman\&view=download\&alias $=15842$-manual-operacional-de-educacaointegral2014\&category slug=junho -2014-pdf\&ltemid=30192.. .

BRASIL. Ministério da Saúde. Agência Nacional de Vigilância Sanitária. Resolução RDC n‥ 306, de 07 de dezembro de 2004. Dispõe sobre o Regulamento técnico para o gerenciamento de resíduos de serviços de saúde. Brasília, DF: Diário Oficial da União, 10 dez. 2004.

BRASIL FS. Gerência de riscos - análise preliminar de riscos. Rio de Janeiro: Ed. Funcefet - Cefet/RJ.

BRASÍLIA. Trajetórias criativas: jovens de 15 a 17 anos no ensino fundamental: uma proposta metodológica que promove autoria, criação, protagonismo e autonomia: caderno 7: iniciação científica. DUTRA, I.M. et al. (orgs). Brasília: Ministério da Educação, 2014. 18 p.: il.

CAREGNATO, R.C.A; MUTTI, R. Pesquisa qualitativa: análise de discurso versus análise de conteúdo. Texto contexto - enferm., Florianópolis, v. 15, n. 4, p. 679-684, Dez. 2006.

CARVALHO, A.B.M. Integração de sistemas - foco na qualidade, meio ambiente, saúde e segurança. Revista Banas Ambiental, p. 46-52, 2000.

CARVALHO, F.S.R.; FEITOSA, V.P.; SILVA, P.G.B.; SOARES, E.C.S.; FONTELES, C.S.R.; RIBEIRO, T.R.; COSTA, F.W.G. Physicochemical and rheological characterization of different Carnoy's solutions applied in oral and maxillofacial surgery. Journal of Raman Spectroscopy, v. 48, n. 10, p. 13751384, 2017.

CARVALHO, F.S.R.; FEITOSA, V.P.; FONSECA, S.G.C.; ARAÚJO, T.D.V.; SOARES, E.C.S.; FONTELES, C.S.R.; RIBEIRO, T.R.; COSTA, F.W.G. Evaluation of different therapeutic Carnoy's formulations on hard human tissues: A Raman microspectroscopy, microhardness, and scanning electron microscopy study. J Craniomaxillofac Surg, v. 46, n. 5, p. 749-758, 2018.

DE VRIES, B.J.M.; PETERSEN, A.C. Conceptualizing sustainable development: An assessment methodology connecting values, knowledge, worldviews and scenarios. Ecological Economics, v. 68, n. 4, p. 1006-1019, 2009.

DIAS, M.A.R. Meio ambiente e comunicação - a função das universidades. Educação brasileira, Brasília, v. 15, n. 31, p. 117-135, 2. semestre, 1993.

HARTZ, Z.M.A., (org). Avaliação em Saúde: dos modelos conceituais à prática na análise da implantação de programas [online]. Editora FIOCRUZ, Rio de Janeiro, 1997. 132 p. ISBN 85-85676- 36-1. 
FERNANDES, G.S.; AZEVEDO, A.C.P.; CARVALHO, A.C.P.; PINTO, M.L.C. Análise e gerenciamento de efluentes de serviços de radiologia. Radiol Bras, São Paulo, v. 38, n. 5, p. 355-358, 2005.

FERREIRA, C.S. Concepções da iniciação científica no ensino médio: uma proposta de pesquisa. Trab. educ. saúde, Rio de Janeiro, v. 1, n. 1, p. 115130, 2003.

FREITAS, A., et al. Radiologia odontológica. 6aㅗ ed. São Paulo: Artes Médicas, 2004.

GRIGOLETTO, J.C.; SANTOS, C.B.; ALBERTINI, L.B.; TAKAYANAGUI, A.M. M. Situação do gerenciamento de efluentes de processamento radiográfico em serviços de saúde. Radiol Bras, São Paulo, v. 44, n. 5, p. 301-307, 2011.

GRIGOLETTO, J.C. A realidade do gerenciamento de efluentes gerados em serviços de diagnóstico por imagem: em busca de uma gestão integrada e sustentável de resíduos. 2010. Tese (Doutorado em Enfermagem em Saúde Pública) - Escola de Enfermagem de Ribeirão Preto, Universidade de São Paulo, Ribeirão Preto, 2010.

GUEDES, D.F.C; SILVA R.S.; VEIGA M.A.M.S.; SOUZA- NETO, M.D.; PÉCORA, J.D. O papel preto da película radiográfica é um alto risco para o meio ambiente. Rev Assoc Paul Cir Dent. v. 63, n. 3, p. 191-194, 2009.

GUEDES, D.F.; SILVA, R.S.; VEIGA, M.A.M.S.; PECORA, J.D. First detection of lead in black paper from intraoral film: an environmental concern. $\mathbf{J}$ Hazard Mater, v. 170, n. 2-3, p. 855-860,2009.

HOCEVAR, C.M.; RODRIGUEZ, M.T.R. Avaliação de impacto ambiental gerado por efluentes fotográficos e radiológicos em Porto Alegre, RS, Brasil. Eng Sanit Ambient, v. 7, n. 3, p. 139-143, 2002.

KANN, B.; OFFERHAUS, H.L.; WINDBERGS, M.; OTTO, C. Raman microscopy for cellular investigations - From single cell imaging to drug carrier uptake visualization. Advanced Drug Delivery Reviews, v. 89, p. 71-90, 2015.

KASTER, F.P.B.; LUND, R.G.; BALDISSERA, R.F.Z. Radioactive waste management in dental offices from the city of Pelotas (RS, Brazil). Arq Odontol, v. 48, n. 4, p. 242-250, 2012.

KASTER, F.P.B.; BALDISSERA, R.F.Z; LUND, R.G.; Aspectos radiológicos relacionados com a sustentabilidade no serviço odontológico. Revista Brasileira de Pesquisa em Saúde, v. 3, n. 4, p. 54-59, 2011.

KAUPPINEN, J.K.; MOFFATT, D.J.; MANTSCH, H.H.; CAMERON D.G. Fourier Self-Deconvolution: A Method for Resolving Intrinsically Overlapped Bands. Applied Spectroscopy, v. 35, n. 3, p. 271-276, 1981.

KINAKH, V. Supporting change for sustainability in Dentistry. Visions for Sustainability, v. 4: p. 5-12, 2015. 
KONG, K.; KENDALL, C.; STONE, N.; NOTINGHER ,I. Raman spectroscopy for medical diagnostics - From in-vitro biofluid assays to in-vivo cancer detection. Advanced Drug Delivery Reviews, v. 89, p. 121-134, 2015.

MACLUSKEY, M.; DURHAM, J.; BALMER, C.; BELL, A.; COWPE, J.; DAWSON, L.; FREEMAN, C.; HANSON, C.; MCDONAGH, A.; JONES, J.; MILLSOPP, L.; OLIVER, R. Dental student suturing skills: a multicentre trial of a checklist-based assessment. Eur J Dent Educ, v. 15, n. 4, p. 244-9, 2011.

MANZI, F.R.; GUEDES, F.R.; AMBROSANO, G.M B.; ALMEIDA, S.M. Estudo do destino dado aos resíduos dos materiais radiográficos pelo cirurgiãodentista. Rev Assoc Paul Cir Dent, v. 59, n. 3, p. 213-216, 2005.

MENDES, L.E.D. Plano de Gerenciamento de Resíduos de Serviços de Saúde (PGRSS) Consultório Odontológico. Anápolis: Odontologia e Biossegurança, 2005.

SANITÁRIA ANDV. Farmacopeia Brasileira. Brasília: Anvisa; 2010.

SEGRE, M.; FERRAZ, F.C. O conceito de saúde. Rev. Saúde Pública, São Paulo, v. 31, n. 5, p. 538-542, 1997.

SMITH, E.; DENT, G. Modern Raman Spectroscopy - A practical approach. England: John Wiley \& Sons, Inc, p. 225, 2005.

TESCHKE, K.; CHOW, Y.; BRAUER, M.; CHESSOR, E.; HIRTLE, B.; KENNEDY, S.M.; YEUNG, M.C.; WARD, H.D. Exposures and their determinants in radiographic film processing. AlHA $\mathbf{J}$ (Fairfax, Va), v. 63, n. 1, p. 11-21, 2002.

WAAS, T.; VERBRUGGEN, A.; WRIGHT, T. University research for sustainable development: definition and characteristics explored. Journal of Cleaner Production, v. 18, n. 7, p. 629-636, 2010. 